\title{
Intra Abdominal Tuberculosis: The Surgical Audit Of Its Presentation And Management
}

\author{
Md. Mohsen Chowdhury', Md. Zulfiqur Rahman Khan'2, Ruksana Karim', ANM Atai Rabbi ${ }^{4}$
}

\begin{abstract}
:
A retrospective study was carried out at Surjical Department of Bangabandbu Sbeikls Mujib Medical University, from Jan-99 to Jan-03, to find out the various modes of presentation of abdominal tuberculosis and its management. A total of 100 patients (adult + old) and all sexes were included in this study. These patients were divided into twogroups: Sturical group and conservative group. In operative cases, bistopathological examination was also undertaken, complications were also noted. Patients in both the groups were given standard anti-tubercular drugs. Ont of 100 patients 15 were managed consenvativej. While surgery was undertaken in 85 patients. Most were female. The patients who has pulmonary as well as abdominal tubernulosis were $30 \%$. The commonest operative finding was lleocaecal Mass $60 \%$. The most common operative procedure undertaken was Rs. Hemicolectomy. The overall mortality was $5 \%$.
\end{abstract}

\section{Introduction:}

Abdominal tuberculosis is commonly encountered by a surgeon working in Bangladesh and other tropical countries. It poses a significant hazard to the health sector '. The third world countries which are facing the problem of poverty, malnutrition environmental pollution and unhygienic conditions in thickly inhabited arcas, are also having the ${ }^{\prime}$ increasing incidence of TB. Tuberculosis is an infectious discase that has plagued mankind since neolithic times $(8000 \mathrm{BC})^{2}$. It was recognized as a contagious disease by the time of hippocrates (400 BC), when it was termed as 'phthisis' (Greck Phthinien, meaning to waste away). TB remains one of the top three infectious disease killers, every minute of every day, 15 people dic from TB. This translates into 8 million cases

1. Assistant Prof. of Surgery, Bangabandhu Sheikh Mujib Medical University

2. Assistant Prof. of Hepatobiliary \& Pancreatic Surgery, Bangabandhu Sheikh Mujub Medical University

3. Assistant Prof. of Biochemistry, Holy Family Red Crescent Medical College

4. Chairman, Department of Surgery, Bangabandhu Sheikh Mujilb Medical Universicy each year of which 2-2.5 million will die'. More than $90 \%$ of thesc cases occur in developing nations that have poor resources ${ }^{5}$. Accive TB is fatal for upto $50 \%$ of untreated pacients. Abdominal TB is common in Bangladesh and other tropical countries and poses a significant health hazards. This study was undertaken to find out the various modes of presentations of abdominal tuberculosis and their management.

\section{Methodology}

A total of 100 patients were included in this study which was carried in surgical Dept. BSMMU, Dhaka during Jan-99 to Jan-03. The patients included were those with abdominal pain, distention, abdominal mass, vomiting, those with constitutional symptoms like fever, malaise, wet loss, anorexia with evidence of pulmonary /lymphoid TB and histopathological evidence of abdominal TB after exploration. These 100 patients were divided into two groups: surgical groups and conservative groups. Surgical group included all patients who presented with symptoms and sign of intestinal obstruction, abdominal lump or peritonitis. 
Histopathological confirmation was the main stay in diagnosis of TB. Conservative groups included all those who presented with vague abdominal and constitutional symptoms and there was no definite indication for surgery. The diagnosis was supported by laboratory testes like raised ESR, Positive mantoux test, posicive polymcrase chain reaction assay, histopathological evidence of extra-abdominal $\mathrm{TB}$, evidence of pulmonary TB, ctc. Patients in both the groups were given a standard 9 months regimen of anti-tuberculous drugs. The patients, especially treated conservatively, were followed up for change in clinical parameters.

\section{Results:}

Out of 100 patients included in this study, 15 were managed conservatively, whilc surgery was undcrtaken in 85 patients. majority of patients were female ( 70 female and 30 malc) with a mean age of 40 years (range 18-60 years). Clinical presentation in shown in Table -1 .

\begin{tabular}{lcc}
\hline Presconting leature & No. of palients & Peroentage \\
\hline Abdominal pain & 80 & $80 \%$ \\
\hline Abdominal distension & 60 & $60 \%$ \\
\hline Fever & 55 & $55 \%$ \\
\hline Vorniting & 40 & $40 \%$ \\
\hline Abdcrninal mass & 60 & $60 \%$ \\
\hline Perilonits & 21 & $21 \%$ \\
\hline Wet Loss & 30 & $30 \%$ \\
\hline Ascotis & 25 & $25 \%$ \\
\hline Sub-acute intestinal & 20 & $20 \%$ \\
obstruct & 8 & $8 \%$ \\
\hline Intastinal Perforaticn & 1 & $1 \%$ S \\
\hline Per.rectal bleeding & &
\end{tabular}

Table-1 Clinical Presentations of the patients

Signs of intestinal obstruction i.c.-abdominal distension, vomiting, absent or cxaggerated bowel sounds were present in 20 cases $(20 \%)$, 50 paticnts $(50 \%)$, presented with mass in the Rt. iliac fossa without any pain in the abdomen, 10 patients with mass in the Rt. jliac fossa with pain in the abdomen. Rare presentations include chronic diarrhea, intestinal perforation, perrectal blecding. Some patients presented with one or more constitutional symptoms like fever, with malaise, wt loss. L.aboratory tests revealed raised ESR in $80(\%)$. Tuberculin test done in 80 paticnts and was positive in 50 patients and in others it was negative. Chest radiographs were carricd out in all cases and 35 had evidence of pulmonary TB. Plain abdominal radio-graphs showing multiple air fluid levels in $20(20 \%)$ patients. PCR (polymerase chain reaction) assay was done in only $3(3 \%)$ cases of suspected abdominal TB, 2 of them were treated conservativcly. PCR was positive in all three cases. Barium studies were done in 60 cases and the diagnosis of intestinal tuberculosis was suspected in 45 cases from Barium X-ray. The commonest findings were dilated intestinal loops and retracted caccum, colonoscopy was done in 25 cases those who presented with Lump in the Rt. iliac fossa, per-rectal bleeding and diarrhoca. Findings are caecum and ascending colon was inflamed, oedematous and few nodules are seen. Biopsies were taken from all cascs. Ultrasonography was performed in 80 cases-showing thickened caccal wall, ascitis in 25 patients Laparoscopy done in 10 patients and showing multiple tubercles in 7 patients. Biopsy was done in all cases.

15 patients were managed conservatively with standard 9 months regime of Anti-tuberculous therapy. Surgical intervention was performed in 85 paticnts $(85 \%)$. The most common operative findings were ileocaccal mass 60 patients $(60 \%)$, tuberculous on the intestine, messentery, peritoncum, and cnlargement of the messenteric lymp nodes, Ileal perforation, multiple stricture and ascities. Biopsy was taken from all cases (Table-II).

\begin{tabular}{|c|c|c|}
\hline Operative findings & No. ol patients & Percentage \\
\hline leocaecal mass & 60 & $60 \%$ \\
\hline Tubercles on viscera & 20 & $20 \%$ \\
\hline Stricture-intestine & 10 & $10 \%$ \\
\hline lifial perforation & 8 & $8 \%$ \\
\hline Bands/Adhesion & 18 & $18 \%$ \\
\hline Peritonitis & 21 & $21 \%$ \\
\hline Sub-axte intention OSS & 20 & $20 \%$ \\
\hline $\begin{array}{l}\text { Enlargement of the messentric } \\
\text { hmph nodes }\end{array}$ & 30 & $30 \%$ \\
\hline Ascitis & 25 & $25 \%$ \\
\hline
\end{tabular}

Table-II Per-operative findings of the patients 
Various surgical procedures undertaken in these 85 patients are shown in table-III. Colon and jejunum were rarcly involved.

\begin{tabular}{lcc}
\hline \multicolumn{1}{c}{ Procedure performed } & No. of Patients & Percentage \\
\hline $\begin{array}{l}\text { Rt. hemi colectomy and ileocolic } \\
\text { anastomosis } \\
\text { for lump in the lleocaecal area }\end{array}$ & 60 & $60 \%$ \\
\hline $\begin{array}{l}\text { Resection and anastomosis tor } \\
\text { stricture }\end{array}$ & 10 & $10 \%$ \\
\hline lleo-transverse Anastomosis only & 2 & $2 \%$ \\
\hline Primary closure of perforation & 8 & $8 \%$ \\
\hline Stricturcplasty & 5 & $5 \%$ \\
\hline Biopsy of tubercles & 20 & $20 \%$ \\
\hline $\begin{array}{l}\text { Release of Bands and adhesions } \\
\text { along with resection }\end{array}$ & 18 & $18 \%$ \\
\hline
\end{tabular}

Table-III Surgical Procedures

Histopathological evidence of TB was positive in 80 patients. In 5 patients, no conclusive evidence. Post-operatively all patients were treated with antituberculous drugs for 9 months. All patients were followed up during the period of chemotherapy. The overall postoperative mortality was $5 \%$. (3 patients presented with perforation of bowel with diffuse peritonitis and 2 had intestinal obstruction-late cases). Laparotomy was done in all cases.

\section{Discussion:}

Tuberculosis is an ancient infectious disease responsible for significant morbidity and mortality world wide $e^{6,7}$ and is common in our country and other devcloping countries. Majority of the abdominal cases are diagnosed late usually on surgical exploration. High clinical suspicion, sonography, colonoscopy, laparoscopy ${ }^{8,9,10}$ manoeuveres can improve the diagnostic yield. Male to female ratio is variable $^{11,12}$ in different studies. Some document shows high prevalence in young females while others have noted that disease affects both sexes equally, the present study also shows high prevalence amongst female patients. In 1993, WHO declared TB to be a global emergency, the first and only disease to be recognized as such $^{13}$.

Roughly $80 \%$ of $\mathrm{TB}$ cases involve respiratory system, though TB can involve any organ system. Miliary TB can occur in any individual organ, in several organs, or through out the body, including the brain ${ }^{14,15}$. Abdominal TB along with pulmonary $\mathrm{TB}$ is very common in developing countries of south Asia and is commonly encountered by the surgeons in tropical countries ${ }^{16}$. Abdominal TB mimics clinically and radiologically some other conditions like Crohn's discasc ${ }^{17}$. The incidence of pulmonary $\mathrm{TB}$ along with abdominal $\mathrm{TB}$ is variable; it is $35 \%$ in the present study, which is comparable to $21 \%$ documented in another study carried out in Pakistan ${ }^{18}$. Though sex distribution is different (i.e. male to female ration of $1: 17$ versus 1.2 respectively).

About $85 \%$ patients presented with long continued intestinal colic and abdominal mass was the predominant clinical manifestation in this series. A clinical presentation of ulcerative type of intestinal TB is diarrhoea ${ }^{12}$. Conscitutional symptoms such as fever anorexia, and wt loss are common in $60 \%$ to $70 \%{ }^{21}$ pulmonary $\mathrm{TB}$ is associated with abdominal TB in some cases $^{21,22}$ but its absence does not rule out the diagnosis of abdominal $\mathrm{TB}^{23}$. The early age affection in South Asian as compared to Europeans has already been reported ${ }^{24}$.

Results of routine laboratory investigations have been non-specific and thus have not helpful in establishing the diagnosis. However, a positive mantoux test results along with the above mentioned findings, should alert the clinician ${ }^{25}$. Radiographic studies may be helpful but they are non-specific ${ }^{26}$. Abdominal X-RAY is equally inconclusive. Finding of dilated bowel loops, air-fluid levels, calcificd lymph nodes are supporting of positive diagnosis but are nonspecific $^{27}$. Barium studies are more useful supporting a diagnosis of intestinal TB $66 \%$ of the time, the most common findings on Barium enema are a pipe-stem colon and a cone-shaped 
retracted caecum ${ }^{28}$. Abdominal sonography, colonscopy, laparoscopy ${ }^{8,2,10}$ can improve the diagnostic field.

In our study, most patients (85\%) underwent laparotomy because most of them werepresented to us with complications where taberculosis involves the intestine, the ileocaecal area is the most commonest site of the discase Ind half of the cases have a palpable mass due to formation of tuberculoma ${ }^{29}$. In the present study the ileocaecal area was the most common site of involvement, as described and palpable mass was present in $60(60 \%)$ cases. Before the advent of effective antitubercular drugs, surgical management consisted of by pass procedure, with the complications of blind-loop syndrome, malabsorption and perforation ${ }^{3 !}$.

A symptomatic ileocaecal mass should be managed with limited ileocaecal resection ${ }^{31}$. In the present study, we also did limited resection of the affected segment and end to end anastomosis in most of the cases. All patients did well with chemo-therapy. In this series, diagnosis was made histologically.

In a western study tuberculous ascitis has been reported in $42 \%$ cases of abdominal TB. The clinical picture, radiography, ulltra-sonography can help in its diagnosis ${ }^{21}$. In the present study the number of patients with tuberculous ascitis was small $(25 \%)$ as are usually managed by the medical department.

Perforation of tuberculous ulcer is uncommon due to the thickening of the peritoneum and the formation of adhesions to the adjacent tissues ${ }^{21}$. The reported incidence varies from $0-11 \%$, with the terminal Ileum being the most frequent site. But in the present study it was found to be $8 \%$. These perforations represent the changing behavior of the disease and late recognition of the signs and symptoms by the patients. Associated lymphadenitis was found in $30 \%$ of cases. Most of the Authors ${ }^{16,27}$ suggested that anti-tuberculous therapy is the main stay of management of abdominal TB and the surgery should be reserved for diagnosis or for management of complication. Some patients may pass into subacute intestinal obstruction phase after antituberculous therapy due to the fibrosis while healing of tubercular inflammatory lesions is taking place ${ }^{12}$. In our study, no such type of patient was seen.

Perforation of gut secondary to abdominal TB varies in different studies and similarly mortality rates in some cases have becn described from $8 \%$ to $19.4 \%{ }^{32}$. ${ }^{33}$; But in the present study it was found to be $5 \%$.

\section{Conclusion:}

As the incidence of TB is increasing once again especially due to MDR strain, emphasis must bc made to the carly recognition and early treatment. As intra-abdominal TB can mimic various surgical conditions, surgeons living in the endemic areas like Bangladesh must direct their attention to the early recognition and proper treatment of the intra-abdominal TB. Thus improving the out come for patients with the disease.

\section{Reference:}

1. Hossain J: Al-Aska al-Mofleh; Laparoscopy in tuberculous Peritonitis: J-H-SOC-Med: 1992;85(2)89-91.

2. McDermott LJ, Glassroth J, Mehta JB, Dutt AK, Tuberculosis Part-I, Dis MOn 1997;43(3):113-80.

3. CDC-Core curriculum on tuberculosis : What the clinicians should know 4th Edition, US Department of Health and Human Services:2000.

4. Collins HL, Kaufmann SHE. Prospects for better tuberculosis vaccines. Lancet Inf Dis. 2001;1:1-28.

5. Dutt AK. Stead WW. Tuberculosis in the elderly. Med Clin North Am $1993 ; 77(6): 1353-68$. 
6. Cartwell MF. Suider DEJ. Cauthen GM. Epidemiology of Tuberculosis in United States. 1985 through 1992. JAMA, 1994;17;272(2):535-9.

7. Scales D, Sheppard J. Tuberculosis. cMedicine 2001.10:2.

8. Shah S: Thomas V; Mathan M; Chacko; Chandy G; Ramakrishna BS; Rolaston DD; Colonoscopic tudy of 50 Patients with colonic Tuberculosis:Gut; 1992; 33(3):347-51.

9. Nafeh MA; Medhat; abdul hameed AG; Ahmed YA; Rashwar NM; Strickland GT; Tuberculous Peritonitis in Egypt; The Value of oaparoscopy in Diagnosis;Am-J. Trop. Med-Hyg;1992;47(4);470-7.

10. Al-Quoruin AA; Satti MB; al Gindan YM; al Ghamab GA; Al Freihi HM; Tuberculous peritonitis; The Value of laparoscopy:hepatogastro-

enterology;1992;38 Suppl; 37-40.

11. Haddad FS, Ghomain A; Sawaya E, nelson AR; Abdominal Tuberculosis; Discolon Rectum; 1987; 30:724-35.

12. Underwood MJ; Thompson MM; Sayers RD; Hail AW; Presentation of Abdominal Tuberculosis to General Surgeon. Br-JSurg; 1992;79:1077-9.

13. World Health organisation, Global Tuberculosis Control, WHO report 2000.

14. Kim JH, Langston AA, Gallis HA, Miliary tuberculosis; Epiclemiology, Clinical manifestations, diagnosis and outcome. Rev infect Dis 1990;12 (4): 53-90.

15. Talavera W, Leusanau KD, Handwerges S. Extra-pulmonary Tuberculosis: TB current concepts and treatment. Friedman LN Editor, 1994;CRC Press, Florida, USA.
16. Jayarthi V, Robinson RJ, Malthi $\mathrm{S}$, et al. Docs crohn's discase needs differentiation from tuberculosos? J Gastroenterol Hepatal, 1996;11(2):183-6.

17. Bowne B], Tytgat KM, Schipper HG et al. Beware of abdominal tuberculosis. Neth J Med. 1997;51(3):119-22.

18. Tariq NA. Abdominal Tuberculosis, the Surgical Audit of its Presentation Pakistan J Surg 1993; 9(3);82-6.

19. G.R. Nzanubara. Gastrointestinal ruberculosis: An cmerging diagnostic Delemma. East Afr Med J 1998;75(2):124126.

20. Ramesh S. Vecragandham, Frank P. Lynch et al. Abdominal tuberculosis in Children: Review of 26 cases. J Pediatr Surg 1996;31(1): 170-6.

21. Chen WS: Leu Sy: HSUH; Lin JK; LINTC Trend of large Bowel Tuberculosis and the relation with Pulmonary TB. Discolon-Rectum; 1992:35(2):189-92.

22. LEWIS EA, Abioye AA, Tuberculosis of the abdomen in Ibadan: a clinicoPathological review. Tubercle 1975;56149:55.

23. Lambrianides AL; Ackroyd N; Shorey BA Abdominal tuberculosis, $\mathrm{Br} \mathrm{J}$ Surg 1980;67:887-9.

24. Medical Research council Tuberculosis and chest Disease unit. National Survey and wales in 1983: Characteristics of disease. Tubercle 1987;68:19-32.

25. Bhansali SK. Abdominal tuberculosis. Experiences with 300 cases. Am J Gastroenterol 1977;37:324-37. 
Vol. 01, No. 01 July 2003

26. Werbeloff L, Novis BH, Banks S, et al. The radiology of tuberculosis of the gastro-intestinal tract. $\mathrm{Br} . \mathrm{J}$ Radiol 1973;46:329-36.

27. Karen D, Horvath MD, and Richard L, Whelan MD.

Intestinal Tuberculosis; Return of an old Disease. Am J Gastroenterol 1998;93(5):692-6.

28. Kolawole TM, Lewis EA. A radiologic Study of tuberculosis of the Abdomen (gastrointestinal tract). Am J Roentgenol Radium Ther Nucl Med 1975;123:348-58.

29. Howell JS, Knapton PJ. Ileocaecal tuberculosis. Gut 1964;5:524-9.

30. MC Gee GS Lester WF, POHS J, et al. Gastro-intestinal tuberculosis resurgenc of an old Pathogen. Am. Surg 1989;88:989-99.
31. Dandpat MC, Mahapatra SK, Nanda N. Conservative Surgical management of intestinal tuberculosis. J and Med Assoc 1990;88:156-8.

32. Al-Quorian AA. Facharzi SMD Al-Freihi $\mathrm{HM}$ et al. Abdominal tuberculosis in Saudi Arabia:Aclinico-pathological Study of 65 cases. Am J Gastro-interol. 1993;88(i) 75-9

33. Sircar S, Taneja VA, Kansra U. Epidemiology and clinical presentation of Abdominal tuberculosis. A retrospective Study. J india and Med Assoc 1996;94(9):342-4. 